\title{
Biorremediação passiva: um estudo preliminar sobre o óleo vegetal de soja
}

\author{
Passive bioremediation: a preliminary study on waste vegetable oil
}

\author{
Sérgio Thode Filho ${ }^{1}$, Thuanny Moraes de Almeida², Cintia Patrícia Santos da Paixão ${ }^{3}$, \\ Monica Regina da Costa Marques ${ }^{4}$ e Elmo Rodrigues da Silva ${ }^{5}$
}

${ }^{1}$ Discente do PPG-MA da Universidade do Estado do Rio de Janeiro - UERJ. Professor do IFRJ. Laboratório Multidisciplinar de Gerenciamento de Resíduos (LMGR), Brasil

${ }^{2}$ Mestranda em Ciência e Tecnologia de Polímeros - IMA/UFRJ. Discente de Iniciação Científica do LMGR, Brasil

${ }^{3}$ Graduanda em Gestão Industrial pelo IFRJ. Discente de Iniciação Científica do LMGR, Brasil

4,5Professores do PPG-MA da Universidade do Estado do Rio de Janeiro - UERJ , Brasil

\begin{abstract}
Resumo
O crescimento acelerado da população e seu consumo excessivo por bens e serviços têm provocado impactos ambientais cada vez mais significativos. Com isso, os resíduos gerados por ela impactam diretamente o meio urbano e os ambientes naturais. As estimativas de produção de óleo vegetal comestível são de três bilhões de litros por ano no país. No município do Rio de Janeiro, mais de 20 milhões de litros de óleo vegetal são consumidos por ano. Sabe-se que o óleo vegetal residual pode ocasionar danos aos corpos d'água, pois o óleo forma uma camada na superfície que impede a entrada da luz solar, diminuindo a fotossíntese e o oxigênio dissolvido, provocando a morte de organismos aquáticos. Os solos são também impactados quando recebe óleo vegetal virgem ou residual, pois este o impermeabiliza, desestruturando-o e causando enchentes. Uma das técnicas in situ comumente utilizadas para minimizar o impacto nos solos é através da biorremediação passiva ou atenuação natural, na qual o poluente/contaminante permanece no local impactado e, por meio de processos naturais, como biodegradação, volatilização, diluição e sorção, ocorre a descontaminação do ambiente. O presente trabalho objetiva avaliar a técnica de biorremediação natural, utilizando testes in vitro, como forma de remediar um solo contaminado artificialmente com óleo vegetal de soja virgem. A técnica de biorremediação passiva ou atenuação natural mostrou ser uma boa alternativa na descontaminação de ambientes contaminados por óleos vegetais. A taxa de biodegradação do óleo vegetal foi máxima em torno do trigésimo dia. Após este período, a atividade bacteriana aeróbia apresenta diminuição na produção, provavelmente devido ao consumo total de oxigênio do meio.
\end{abstract}

Palavras-chave: Biorremediação passiva, óleos vegetais, resíduos sólidos, contaminação do solo.

\begin{abstract}
The rapid population growth and excessive consumption for goods and services, has anthropized increasingly the environment. Thus, the waste generated by it directly impact the urban and natural environments. The edible vegetable oil production estimates are three billion liters per year in the country. In the city of Rio de Janeiro, more than 20 million liters of vegetable oil are consumed per year. It is known that the waste vegetable oil can cause damage to water bodies, because the oil forms a layer on the surface that prevents the entry of sunlight, reducing photosynthesis and dissolved oxygen, killing aquatic organisms. The soils are also impacted when receiving virgin or waste vegetable oil, as this waterproofs, disrupting and causing flooding. One of the techniques commonly used in situ bioremediation is passive or natural attenuation, at which the pollutant/contaminant remains on the impacted site and by natural processes, such as biodegradation, volatilization, adsorption and dilution, decontamination of the environment occurs. This study aims to evaluate the technique of natural bioremediation, using in vitro tests, in order to remedy an artificially contaminated soil with vegetable oil virgin soy. The passive bioremediation technique or natural attenuation proved to be a good alternative in the decontamination of environments contaminated by vegetable oils. The biodegradation rate of vegetable oil was maximum around the thirtieth day. After this period, the aerobic bacterial activity has decreased production, probably due to the total consumption of oxygen of the medium.
\end{abstract}

Keywords: Passive bioremediation, vegetable oils, solid waste, soil contamination. 


\section{Introdução}

$\mathrm{O}$ crescimento acelerado da população e seu consumo excessivo de por bens e serviços, tem provocado o aumento do processo antropização. Com isso, os resíduos gerados por ela impactam diretamente o meio urbano e os ambientes naturais. Durante muito tempo houve uma disposição inadequada dos resíduos gerados, sobretudo os perigosos, sem nenhuma preocupação ambiental, ocasionando poluição/contaminação do solo e de todo ecossistema (BRAGA et al., 2002).

As estimativas de produção de óleo vegetal comestível são de três bilhões de litros por ano no país. No município do Rio de Janeiro, mais de 20 milhões de litros de óleo vegetal são consumidos por ano (FOLHA DO CENTRO, 2009; ABIOVE, 2012).

Sabe-se que o óleo vegetal residual, ao ser lançado na rede de esgoto, pode provocar o entupimento das tubulações e aumentar em até $45 \%$ os custos de tratamento dos esgotos (SABESP, 2011). Além disso, pode ocasionar danos aos corpos d'água, pois o óleo forma uma camada na superfície que impede a entrada da luz solar, diminuindo a fotossíntese e o oxigênio dissolvido, provocando a morte de organismos aquáticos (QI et al., 2009). Os solos são também impactados quando recebem óleo vegetal virgem ou residual, pois este o impermeabiliza, desestruturando e causando enchentes (FIGUEIREDO, 1995; FOLHA DO AMAPÁ, 2007; NOGUEIRA e BEBER, 2009; GALBIATI, 2012).

Com a finalidade de eliminar ou mitigar os impactos causados ao ambiente se faz necessária a utilização de algumas técnicas que permitam a sua recomposição, já que o tempo natural de regeneração do solo é bastante elevado. A escolha da melhor técnica remediadora depende das características do solo, do poluente e contaminante das questões econômicas (BAIRD, 2002).

Uma das técnicas in situ comumente utilizadas é a biorremediação passiva ou atenuação natural, na qual o poluente/contaminante permanece no local impactado e, por meio de processos naturais, como biodegradação, volatilização, diluição e sorção, ocorre a descontaminação do ambiente (MULLIGAN; YONG, 2004).O presente trabalho objetiva avaliar a técnica de biorremediação natural, utilizando testes in vitro, como forma de remediar um solo contaminado artificialmente com óleo vegetal de soja virgem.

\section{Metodologia}

A coleta do solo do tipo argissolo foi feita no município de Resende, RJ, a uma profundidade de $0-60 \mathrm{~cm}$. Para realização deste experimento, foram pesados em pote hermético de $2 \mathrm{~L}, 500 \mathrm{~g}$ de solo contaminados artificialmente com 12,5 mL de óleo de soja virgem. Adicionalmente, foi colocado acima do solo contaminado um pote aberto de 115 g contendo $20 \mathrm{~mL}$ da solução de $\mathrm{NaOH}$
0,40 mol/L, com o objetivo de capturar o $\mathrm{CO}_{2}$ produzido na remediação. Após três datas pré-estabelecidas (15 dias, 30 dias, 45 dias e 60 dias após a data de início do experimento) os recipientes foram abertos para determinação da quantidade de $\mathrm{CO}_{2}$ produzida durante este período. Todos os experimentos foram realizados em duplicata. Sendo que para cada duplicata, existia um experimento em branco ou testemunho em que foi adicionado o solo sem contaminação. Este experimento teve como objetivo determinar a quantidade $\mathrm{CO}_{2}$ existente na atmosfera. Após este período, adicionava-se neste $1 \mathrm{~mL}$ de $\mathrm{BaCl}_{2} 1 \mathrm{~mol} / \mathrm{L}$ e mais 2 gotas do indicador de fenolftaleína à solução de hidróxido, para posterior titulação com a solução de $\mathrm{HCl}, 40 \mathrm{~mol} / \mathrm{L}$. A quantidade de $\mathrm{HCl}(\mathrm{mL})$ utilizada na titulação para neutralizar o $\mathrm{NaOH}$ restante corresponde ao que não reagiu com o $\mathrm{CO}_{2} \mathrm{e}$, portanto, por diferença obtém-se o $\mathrm{CO}_{2}$ produzido (Eq.1).

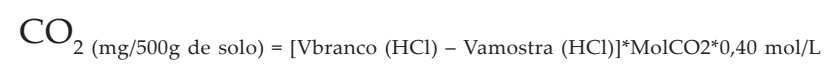
$\left.(\mathrm{HCl})^{*}[\mathrm{HCl}] / \mathrm{NaOH}\right]$

\section{Resultado e Discussão}

As titulações para verificação de captura de $\mathrm{CO}_{2}$ foram realizadas 15, 3045 e 60 dias, respectivamente após a data de início (Tabela 1). Após quinze dias, observa-se que houve uma captura de $0,0050 \mathrm{CO}_{2}(\mathrm{mg} / 500 \mathrm{~g}$ de solo), já após 30 dias, a captura foi bem maior, $0,0300 \mathrm{CO}_{2}$ (mg/500g de solo), representando um aumento de $83 \%$ em relação ao primeiro período de análise (15 dias). No terceiro período de análise (45 dias) constata-se um valor de $0,0122 \mathrm{CO}_{2}(\mathrm{mg} / 500 \mathrm{~g}$ de solo), ou seja, uma queda de $41 \%$ em relação ao segundo período de análise (30 dias), porém um aumento de $41 \%$ em relação ao primeiro período de análise (15 dias). No último período de análise, isto é, 60 dias após o início do experimento, não foi observado mais captura de $\mathrm{CO}_{2}$.

Tabela 1 - Captura de $\mathrm{CO}_{2}$ durante a biorremediação de um solo contaminado com óleo vegetal

\begin{tabular}{cc}
\hline $\begin{array}{c}\text { Tempo } \\
\text { (Dias) }\end{array}$ & $\begin{array}{c}\text { Captura de } \mathrm{CO}_{2} \\
(\mathrm{mg} / 500 \mathrm{~g} \text { de solo })\end{array}$ \\
\hline 15 & 0,0050 \\
30 & 0,0300 \\
45 & 0,0122 \\
60 & 0 \\
\hline
\end{tabular}

A figura 1 apresenta o comportamento da captura de $\mathrm{CO}_{2}$ neste período. Observa-se que o comportamento

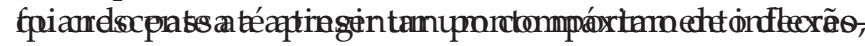




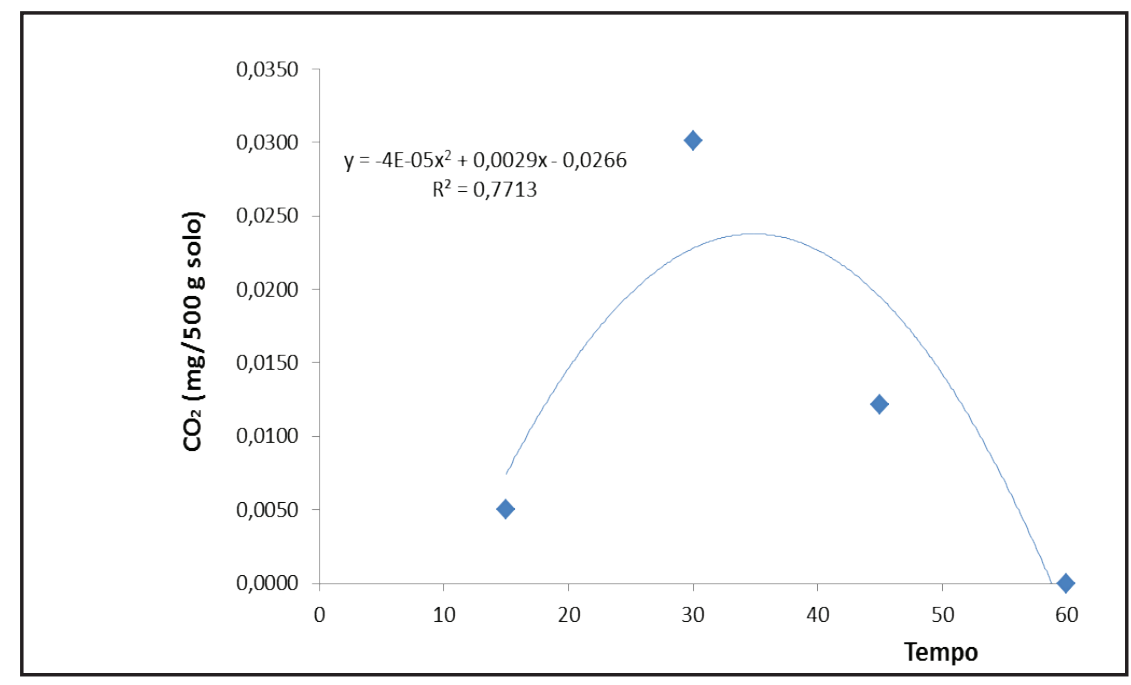

Figura 1 - Gráfico referente à captura de $\mathrm{CO}_{2}$ em função do tempo

cente. A tendência quadrática desta função demonstra um decrescimento até um determinado período em que não ocorreu mais produção de $\mathrm{CO}_{2}$. Constatou-se que este tempo encontra-se no intervalo entre o quadragésimo quinto e o sexagésimo dia. A função polinomial do segundo grau apresenta em um nível satisfatório de confiança, com $\mathrm{R}^{2}$ igual a 0,7713 .

Verifica-se que a variável dependente $\mathrm{CO}_{2}$ apresenta variação em função do tempo, de acordo com a função apresentada para um domínio trabalhado entre 15 e 60 dias.

Assim, o decréscimo de $\mathrm{CO}_{2}$ após um pico no trigésimo dia e a redução de $\mathrm{CO}_{2}$ à zero após 60 dias de experimento sugere que os micro-organismos aeróbios têm participação direta no consumo do poluente. As bactérias aeróbicas de rápido crescimento devem ter consumido todo $\mathrm{o} \mathrm{O}_{2}$ presente no frasco até o trigésimo dia. Após este período, apenas as bactérias anaeróbicas participaram do processo e não produziram $\mathrm{CO}_{2}$, uma vez que não utilizam o oxigênio como aceptor de elétrons. Mariano et al. (2007) estudando a biorremediação de solos contaminados com óleo diesel proveniente de postos de combustíveis observaram um crescente acúmulo de $\mathrm{CO}_{2}$ até o fim do experimento (55 dias). Os autores constataram que conforme determinadas fontes de hidrocarbonetos são consumidas, diminuindo sua biodisponibilidade, os microorganismos adaptamse a outras fontes, resultando em uma diminuição da produção de $\mathrm{CO}_{2}$.

Um estudo sobre bioaumentação e atenuação natural realizado por Deon et al (2012) apresenta um Latossolo Vermelho Distrófico Típico, pH em torno de 5,4 que foi contaminado artificialmente com óleo diesel, óleo lubrificante e óleo de soja de soja. Os ensaios foram realizados utilizando-se solo de $500 \mathrm{~g}$, no qual foi adicionado com $50 \mathrm{~mL}(10 \%)$ de contaminante e tratadoas por atenuação natural e bioaumentação. Os experimentos foram realizados em duplicata, durante 21 dias. A umidade foi ajustada semanalmente até $60 \%$ com adição de água e a aeração foi promovida pela mistura manual do solo com auxílio de espátula. Verificou-se que o óleo de soja foi o contaminante mais facilmente removido do solo independente do processo de biorremediação utilizado. A técnica de atenuação natural atingiu um percentual de $49,45 \%$ de remoção de óleo.

\section{Conclusão}

A técnica de biorremediação passiva ou atenuação natural mostrou ser uma boa alternativa na descontaminação de ambientes contendo óleos vegetais. A taxa de biodegradação do óleo vegetal foi máxima em torno do trigésimo dia. Após este período, a atividade bacteriana aeróbia apresenta diminuição na produção, provavelmente devido ao consumo total de oxigênio do meio.

\section{Referências}

Abiove. Associação Brasileira das Indústrias de Óleos Vegetais. (2012). Disponível em: <http:// www.abiove. com.br/menu_br.html>. Acesso em: 18 jan. 2015.

Abrelpe. (2013). Panorama dos Resíduos Sólidos do Brasil. São Paulo: ABRELPE.

Baird, C. (2002). Química Ambiental. 2. ed. Porto Alegre: Bookma, $622 \mathrm{p}$.

Braga, B. et al. (2002). Introdução à engenharia ambiental. São Paulo: Prentice Hall. p. 145-150.

Deon, Maitê Carla et al. (2012). Biorremediação de solos contaminados com resíduos oleosos através de bioaumentação e atenuação natural. Semina: Ciências 
Exatas e Tecnológicas, v. 33, n. 1, p. 73-82.

Figueiredo, P. M. (1995). A sociedade do lixo: os resíduos, a questão energética e a crise ambiental. São Paulo: Unimep.

Folha do centro. (2009). Esgoto não é lugar de óleo de cozinha. Disponível em: <http://www. jornalfolhadocentro.com.br>. Acesso em: 20 mar. 2015.

Folha do Amapá. (2007). Óleo de cozinha usado contamina solo água e atmosfera. Disponível em: <http://www. folhadoamapa.com.br>. Acesso em: 21 jul. 2012.

Sabesp. (2011). Reciclagem de óleo de cozinha. Disponível em: <http://site.sabesp.com.br>. Acesso em: 10 abr. 2015.

Galbiati, A. F. (2005). O gerenciamento integrado de resíduos sólidos e a reciclagem. Disponível em: $<$ http:// www.redeaguape.org.br>. Acesso em: 21 jul. 2012.

Mariano, Adriano Pinto et al. (2007). Laboratory study on the bioremediation of diesel oil contaminated soil from a petrol station. Brazilian Journal of Microbiology, v. 38, n. 2, p. 346-353.

Mulligan, C. N.; YONG, R. N. (2004). Natural attenuation of contaminated soil. Environmental International, Oxford, v.30, n. 4, p. 587-601, Apr.

Nogueira, G. R.; Beber, J. (2009). Proposta de metodologia para o gerenciamento de óleo vegetal residual oriundo de frituras. Tese de Mestrado em Bioenergia. Universidade Estadual do Centro-Oeste do Paraná, Irati. Disponível em: <http://www.unicentro.br>. Acesso em: 10 abr. 2015. 